https://doi.org/10.24201/aap.2021.331

INFORME

\title{
Singapur 2020: Tiempos difíciles
}

\section{Singapore 2020: Hard Times}

NORMAN VASU

Nanyang Technological University, Singapur

https://orcid.org/0000-0003-1253-2883

Recepción: 6 de diciembre de 2020

Aceptación: 15 de diciembre de 2020

Resumen: En 2020, Singapur experimentó algunos desafíos en relación con la pandemia y las relaciones comunales, el statu quo sufrió algunas ligeras modificaciones debido a los resultados de las elecciones parlamentarias y vio pocos vientos en contra y disruptivos en sus relaciones exteriores.

Palabras clave: Singapur; política; relaciones comunales; covid-19.

\begin{abstract}
Singapore's 2020 has experienced some challenges with regard to the pandemic and communal relations, undergone some slight political alteration to the statu quo due to the results of the Parliamentary elections it held, and saw little disruptive headwinds in terms of foreign relations.
\end{abstract}

Keywords: Singapore; Policy; communal relations; Covid-19.

Podría decirse que el año 2020 en Singapur, al igual que en la mayoría de los Estados del mundo, fue desafiante, por decirlo suavemente. La pandemia ha sido un reto en el ámbito 
social y el económico. Las elecciones generales que se llevaron a cabo a mediados de año fueron desafiantes para el partido en el poder, pues sus resultados fueron más bien negativos. El mantenimiento de la armonía social en la ciudad-Estado multicultural ha sido un reto, dado que la xenofobia está creciendo entre sus ciudadanos. Quizá un elemento que ha dado motivos de optimismo está en el ámbito de las relaciones exteriores: el trato de Singapur con Malasia e Indonesia, sus vecinos más cercanos, así como con Estados Unidos y China, las dos grandes potencias de la región, ha gozado de estabilidad.

\section{Covid-19}

El país tuvo su primer caso de coronavirus en enero de 2020 y el gobierno respondió rápidamente. Entre enero y fines de marzo se realizaron pruebas a los viajeros que llegaban a Singapur y se puso en cuarentena a quienes tenían un resultado positivo, así como a quienes no tenían síntomas pero habían estado expuestos al virus. Además se tomaron otras medidas que incluyeron el rastreo de contactos, la recomendación de retrasar todos los viajes, el cierre de todas las fronteras, la cancelación de grandes eventos públicos y el cierre de los lugares de entretenimiento.

Esta respuesta inicial a la pandemia se describió como "pronta y ágil”, lo que le valió a Singapur elogios en el ámbito internacional, tanto de la Organización Mundial de la Salud como de la escritora científica y experta en epidemias Laurie Garrett, ganadora del premio Pulitzer. Garrett declaró que "si Singapur no lo logra, si Singapur no puede mantenerlo bajo control, todos estamos jodidos porque ellos tienen el mejor sistema del mundo" (Koay y Lay 2020; Cher 2020; Leonhardt 2020). La respuesta, que sobre todo fue competente e inmediatamente posterior a la detección del virus, no debió haber sido una sorpresa. La ciudad-Estado se había preparado para un suceso de este tipo desde que vivió el trauma de la epidemia del síndrome respiratorio agudo severo (SARS), que afectó a varios países del mundo los primeros años de la década de 2000. El SARS, que se ha descrito como un "ensayo general” para la covid-19, afectó a 238 personas en Singapur, mató a 33 y le costó a la economía cerca de 1000 millones de dólares singapurenses (Barron 2020). 
Se han realizado pruebas de manera masiva. Los datos del 20 de marzo muestran que se habían realizado 6800 pruebas por cada millón de habitantes, en comparación con las 300 pruebas por millón de habitantes que se realizan en Estados Unidos. Rápidamente se prohibieron las llegadas de visitantes de corta estadía y se ha pedido que los residentes que vuelvan al país permanezcan durante 14 días en habitaciones de hotel provistas por el gobierno. El rastreo de contactos ha sido extenso, para lo cual las autoridades utilizan una aplicación de teléfono celular que monitorea si los pacientes de coronavirus han estado en contacto cercano con personas que no se han contagiado. Para atajar la tasa y el número de contagios, el 7 de abril se introdujo un confinamiento parcial de cuatro semanas en todo el Estado - que el gobierno denominó "cortacircuitos". Durante el cortacircuitos, que efectivamente fue un cordón sanitario, el gobierno ordenó la implementación de las siguientes medidas: uso obligatorio de cubrebocas en público, impartición de clases en línea, cierre de piscinas, parques y playas, trabajo desde casa y servicio de restaurante únicamente para llevar. Asimismo, se anunciaron diversos paquetes de estímulos económicos para suavizar el impacto de dichas acciones. A inicios de mayo se levantaron progresivamente las restricciones del cortacircuitos.

Sin embargo, para mediados de abril el número de casos había ascendido a más de 10000 y convirtió a Singapur en el país más afectado del Sureste Asiático en ese momento (Ratcliffe 2020), lo que comprueba el adagio de que ningún plan sobrevive al primer contacto con el enemigo. La mayoría de los nuevos casos reportados eran de trabajadores migrantes, a los que se denomina la "columna vertebral de los sectores de la construcción, los astilleros y el procesamiento en Singapur" y que efectivamente se emplean para realizar trabajos que los singapurenses consideran sucios, difíciles y peligrosos (Lim M. Z. 2020). El contagio de los trabajadores migrantes fue alarmante para los funcionarios de salud, pues representan una parte importante de la población de Singapur — para 2019 componían 56\% (alrededor de 914 000) del 1.68 millones de habitantes que no son residentes (Tan, E. K. B. 2020). El contagio de los trabajadores migrantes expuso un error colosal en la respuesta de Singapur a la covid-19: no se tomó en cuenta su vulnerabilidad al contagio debida al hacinamiento de los dormitorios donde se les aloja, que hace imposible poner en práctica el distanciamiento social (Fordyce 2020). 
Al momento en que se escribe el presente, ${ }^{1}$ Singapur está operando en una etapa de “Transición segura” en la que siguen en vigor el rastreo de contactos, los límites al número de personas que pueden asistir a eventos y las medidas de cuarentena. No se prevé un regreso a una aproximación de lo que era normal antes de la pandemia hasta que se encuentre un tratamiento o una vacuna efectivos. No ha habido transmisión comunitaria, 28 personas permanecen hospitalizadas y 29 han perdido la vida. Si bien quizá sea demasiado pronto para ofrecer una evaluación exhaustiva de la gestión de la pandemia por parte del gobierno de Singapur, es posible anotar algunos elementos del balance.

En relación con las pruebas positivas, hay tres elementos de la respuesta del gobierno que merecen elogio. En primer lugar, al parecer la coordinación y la cooperación entre varios organismos de gobierno han sido muy tersas. Por ejemplo, debido al aprendizaje con el SARS de que la coordinación entre ministerios de gobierno es clave para que la respuesta sea robusta y efectiva, se creó una Fuerza de Tareas Multiministerial para garantizar la colaboración entre agencias al enfrentar el complejo desafío que planteaba el virus apenas 22 días después de que China reportara a la Organización Mundial de la Salud que se habían detectado casos de neumonía grave en Wuhan, provincia de Hubei (Low, J. 2020). Además, esta estructura burocrática se complementó con una arraigada cultura de cooperación entre instituciones para limitar la rivalidad entre ellas y que cada una defendiera su propio ámbito (Hong 2017).

En segundo lugar, la comunicación clara y transparente ha sido otro elemento positivo de la respuesta hasta ahora. El primer ministro (PM) y los mandos siguientes en la cadena de liderazgo se han comunicado con el público con base en hechos y de manera constante, tranquilizadora e inequívoca: se ha transmitido lo que se sabía del virus, se expuso lo que podía hacerse y se reconoció lo que se desconocía (Heijmans y Gale 2020). La comunicación clara ha hecho que la mayor parte del público confíe en que se está haciendo todo lo posible. Además, comunicar a la gente cómo podía contribuir a través del distanciamiento social y el uso de cubrebocas facilitó la recuperación de un cierto nivel de control entre quienes sintieron una disminución en su capacidad agentiva e impotencia frente a la pandemia.

\footnotetext{
${ }^{1} 5$ de diciembre de 2020 .
} 
En tercer lugar, ciertamente el gobierno de Singapur no ha sido tacaño fiscalmente en sus intentos por estabilizar, estimular y apoyar a la economía. Con la expectativa de que su economía, que depende del comercio, se contraiga entre 5\% y 7\% este año —una caída que causaría la peor recesión desde 1964 - hasta ahora el gobierno ha anunciado cuatro paquetes de estímulos destinados a proteger tanto a las empresas como a los empleados (Yen 2020b).

Heng Swee Keat, el ministro de Finanzas, ha descrito los cuatro paquetes como una “respuesta necesaria a una crisis sin precedentes" (Kok 2020), ascienden a \$65 400 millones de dólares, lo que representa 19.2\% del producto interno bruto (PIB). Estos paquetes, denominados presupuestos de "Unidad", "Resiliencia", "Solidaridad" y "Fortaleza", se han destinado a medidas como el subsidio de salarios, la disminución a los impuestos sobre la propiedad, "créditos al turismo" para fomentar el turismo nacional y pagos en efectivo a desempleados, a quienes han sufrido una pérdida de ingresos significativa y a trabajadores con salarios bajos.

En cuanto a los puntos negativos del balance, los dos más obvios son la evaluación incorrecta del virus como algo tan grave parecido a la gripe común y la disuasión activa del uso de cubrebocas en un inicio (Today 2020b). Si bien estos dos errores pueden explicarse como decisiones infortunadas comprensibles que suceden inevitablemente cuando se aborda el desafío fluido y desconocido de un nuevo virus, quizá sea más difícil alcanzar la exoneración por no anticiparse al hecho de que los dormitorios para trabajadores extranjeros serían un grave vector de contagio (Griffiths 2020). El fracaso es especialmente grave si se considera que la organización no gubernamental (ONG) Transient Workers Count Too (TWC2) [Los trabajadores temporales también cuentan] señaló esta vulnerabilidad mucho antes de que comenzaran los contagios y la diseminación rápida del virus (Fordcye 2020). Un analista explicó como una "mezcla de optimismo delirante y negación" la decisión de no actuar ante el reporte de TWC2, que alertaba sobre el hecho de que las condiciones de vida de los trabajadores extranjeros los convertía en una bomba de tiempo al inicio de la pandemia (Low, D. 2020). Si bien el exceso de autoconfianza puede surgir de una desafortunada arrogancia o de una apabullante falta de juicio, la negación revela un problema más profundo y arraigado de la sociedad singapurense - un problema cultural de complacencia, pues el gobierno se resiste a considerar perspectivas alternativas porque cree tener la razón, aunado a un público 
callado, acrítico y transigente. ${ }^{2}$ Esta combinación es especialmente problemática cuando se opera en un entorno complejo donde la suma de múltiples puntos de vista ofrece más utilidad para resolver los problemas que las soluciones que presentan unos cuantos (Surowiecki 2004).

\section{SOCIEDAD: UNA MIRADA A LO EXTRANJERO Y A BLM}

Al igual que muchos otros Estados, Singapur ha experimentado tensión en las líneas de falla sociales debido a que los singapurenses ahora ven con desagrado el número de extranjeros que habitan el Estado. En relación con los extranjeros que viven entre ellos, muchas personas que, al parecer, intentan encontrar una lógica a la pandemia y a la caída de la economía han recurrido a la opción xenofóbica y simplista de culpar al "otro" extranjero en esta ciudadEstado multicultural y multinacional. Se ha responsabilizado a los trabajadores extranjeros, que reciben salarios bajos, por la tasa de contagios alta, y a los migrantes calificados por la incapacidad de los singapurenses para encontrar empleo.

Dado que es una nación de inmigrantes desde su fundación como centro comercial británico en 1819, los inmigrantes son prácticamente omnipresentes en Singapur, donde sólo hay 3.5 millones de ciudadanos en una población total de 5.7 millones. La inmigración a gran escala que se presentó después de la independencia de 1965 puede explicarse con los cambios del gobierno a las políticas desde finales de la década de 1980. El gobierno de Singapur ha estado en favor de la inmigración por cuatro motivos: 1) el deseo de ampliar la reserva de talento disponible para la industria; 2) para seguir siendo competitivos ante otros países con bases de mano de obra barata más amplias; 3) para suplementar la baja tasa de fertilidad total, que actualmente se encuentra muy por debajo del nivel de remplazo; 4) para mantener la demografía racial al nivel fundado en la independencia (Lee, H. L. 2010; Straits Times 1989; Bellows 1990). Además de estas cuatro metas, una quinta que no suele discutirse se ha

\footnotetext{
${ }^{2}$ La resistencia a otros puntos de vista se puso de manifiesto cuando Josephine Teo, ministra del Trabajo (MT), sostuvo en el Parlamento que los trabajadores extranjeros recibían un buen trato y que su bienestar estaba "en el radar" de su ministerio ya a principios del año. Además, Teo, mostrando que es incapaz de percatarse de que las relaciones desiguales de poder pueden afectar la franqueza de las discusiones, afirmó que "no se ha encontrado con un solo trabajador migrante que le haya exigido una disculpa". https://www.todayonline.com/singapore/welfare-migrant-workers-was-radar-early$\underline{\text { mom-will-see-how-standards-can-be-raised-josephine }}$
} 
descrito como "demografía Ponzi" — la necesidad continua e implacable de aumentar la población de un Estado para impulsar la demanda de bienes y servicios (Persek 2013).

La inmigración moderna en Singapur se divide en dos clases. La primera de ellas es la de los gastarbeiter poco calificados — denominados con el eufemismo de "trabajadores extranjeros"- que entran al país bajo contratos que limitan la duración de su estadía y tienen la posibilidad de adquirir la ciudadanía. Los que pertenecen a este grupo tienen que ver con la segunda meta del gobierno, descrita anteriormente: permiten que Singapur conserve su competitividad ante países cuya mano de obra es menos costosa. La gran mayoría de estos trabajadores son mencionados en el apartado anterior, que se vieron sumamente afectados por el estallido de la pandemia y realizan labores sucias, peligrosas y difíciles (conocidas como "3D" por sus siglas en inglés: dirty, dangerous, difficult). La segunda clase de inmigrantes - a quienes internamente se denomina "talento extranjero" - ayudan a la consecución de las otras tres metas que ya se explicaron. Éstos entran a la fuerza laboral en los sectores profesional, gerencial, ejecutivo y técnico (PGET) de la economía con permisos menos restrictivos, pues algunos reciben estatus de residente permanente, y otros, la ciudadanía. Se considera que estos migrantes suplementan la fuerza laboral calificada de Singapur para que el Estado siga siendo competitivo económicamente. Además se sostiene que su presencia es necesaria, pues la población de Singapur envejece rápidamente y su tasa total de fecundidad (TFR, por sus siglas en inglés) de 1.14 hijos por mujer se encuentra muy por debajo del nivel de remplazo, que es de 2.1 (Singapore Department of Statistics s. f.). Esta población que disminuye, aunada a las presiones socioeconómicas que suelen asociarse con las pirámides poblacionales invertidas en desarrollo, podría afectar el crecimiento económico.

Por otro lado, hay que reconocer que la xenofobia no es novedad en Singapur. En la última década se han visto cada vez más expresiones públicas de hostilidad hacia los extranjeros. Por ejemplo, los que no son ciudadanos han sufrido numerosas acusaciones: como que son malos vecinos, hacen que suban los precios de la vivienda, aumentan la competencia por los lugares en las escuelas, inundan el transporte público, se infiltran en los partidos políticos e incluso permiten que las escuelas ganen competencias deportivas 
interescolares sin merecerlo (Moore 2011; Jones 2010; Lur 2011; Hodal 2013; Teo, C. W. y Chan 2011; Teh y Lim 2011; Seah 2009).

La angustia por la pandemia se ha manifestado en lo que algunos han descrito como un estado de pánico moral, en el que se percibe a ciertos grupos como una amenaza para los puntos de vista y los intereses de la sociedad (Mathews y Zainuddin 2020). Con la pandemia, ninguna de las clases de extranjeros en Singapur — los trabajadores extranjeros y el talento extranjero- se ha librado de lo que un ministro denominó una "reacción visceral" negativa por parte de los singapurenses (Tai 2020).

En la opinión de los trabajadores extranjeros, algunos singapurenses creían que eran ellos, no el gobierno, los culpables de la alta tasa de contagios en los dormitorios. La carta en mandarín de un lector del periódico Lianhe Zaobao, publicada cuando los contagios aumentaron significativamente en los dormitorios, resumió los puntos de vista de algunos sectores de la sociedad del país. La carta sostenía que estos trabajadores provenían de "países retrasados", tenían la "costumbre de reunirse para comer y charlar" y habían traído consigo “malos hábitos de higiene personal” (Lee, J. 2020). La página de Facebook de un periódico mostró que una gran mayoría de los comentarios hacían eco del punto de vista expresado, lo que sugiere que no se trataba de un caso aislado. La controversia que causó la carta incluso dio lugar a la intervención del ministro de Leyes y Asuntos Interiores, quien condenó la opinión por considerarla "xenofóbica y profundamente insensible", y subrayó que el motivo de los altos niveles de contagio era la proximidad con la que vivían los trabajadores en los dormitorios (Lim, Y. L. 2020a).

Ante la grave caída de la economía, las dificultades en el mercado del empleo y los recortes en aumento, los extranjeros que laboran en sectores PGET no han escapado a los insultos xenofóbicos, que se expresan principalmente en línea. Debido a la percepción de que muchos extranjeros ocupan posiciones gerenciales de alto nivel en las compañías de Singapur, algunos ciudadanos indios, empleados de dos bancos y de Temasek Holdings, empresa de inversión del Estado, fueron víctimas de doxing [revelación en línea de información personal de otra persona, N. de la T.] (Today 2020a). De hecho, los indios parecen estar llevándose la peor parte de la cólera xenofóbica, pues se percibe que están sobrerrepresentados en el sector bancario y el tecnológico (Khan 2020). Quienes expresan 
estas visiones xenofóbicas contra los profesionistas extranjeros infortunadamente podrían verse alentados por el comentario del ministro de Relaciones Exteriores de Singapur: "Sólo tenemos extranjeros para darle un viento extra a nuestras velas cuando se da la oportunidad... pero ahora estamos en una tormenta y debemos soltar lastre... 60000 extranjeros han perdido su empleo. Y los esquemas que hemos implementado... claramente [están] dirigidos a los singapurenses" (Abu Baker y Chia 2020).

Además de la xenofobia, en lo relativo al tejido social, Singapur también ha sentido las repercusiones del asesinato de George Floyd en Estados Unidos y la amplificación internacional del movimiento Black Lives Matter [Las vidas negras importan; BLM por sus siglas en inglés]. En el contexto de Singapur, el mensaje mundial antirracismo hizo eco en algunos segmentos de la sociedad, lo que llevó a una discusión más amplia de la experiencia de las minorías, el trato que reciben los trabajadores extranjeros y cómo debe entenderse el pasado colonial del país (Vasu y Wong 2020). Por ejemplo, tras el surgimiento del movimiento BLM apareció en las redes una fotografía que muestra a alumnos de una escuela preparatoria con máscaras negras y la cara pintada de negro para celebrar el cumpleaños de un compañero de origen indio. El ministro de Educación habló al respecto y, si bien reconoció la existencia de sensibilidades raciales en el país, enfatizó las diferencias históricas y de contexto entre Singapur y Estados Unidos (Zhang 2020). Además, dado que el BLM también ha inspirado la lucha contra la supremacía blanca, Singapur, como otros Estados, se ha visto forzado a confrontar su tratamiento y comprensión de las historias coloniales. En el contexto de Singapur se ha cuestionado qué tan apropiado es conmemorar a Stamford Raffles estadista británico, considerado el padre del Singapur moderno - con una estatua, teniendo en cuenta su legado imperial racista (Sholihyn 2020a).

\section{PolíticA INTERIOR-ELECCIONES GENERALES}

El suceso político más notable en 2020 en Singapur fueron las elecciones generales (EG2020) que se llevaron a cabo el 10 de julio para decidir cuál sería el gobierno. En éstas hubo un cambio significativo — para los estándares de las elecciones en el país- en el electorado, que se alejó del Partido de Acción Popular (PAP), que estaba bien arraigado en el poder. El Partido de Acción Popular (PAP), que ha gobernado Singapur desde 1959, perdió 10 de los 
93 escaños parlamentarios disponibles ante el principal partido opositor, el Partido de los Trabajadores (PT). En el sistema de gobernanza híbrido de Westminster que tiene Singapur, el PT triunfó porque obtuvo dos Circunscripciones de Representación Grupal (CRG) circunscripciones de varios miembros en las que los votantes eligen al equipo de candidatos de un partido, no a una sola persona-, así como un escaño de un solo miembro. En una de las primeras elecciones que hubo en el mundo durante la crisis sanitaria por la covid-19, el PAP tuvo uno de los peores resultados de su historia en una elección general, pues su proporción de voto popular pasó de $69.9 \%$ en la última elección de 2015 , a $61.2 \%$. Las EG2020 tuvieron una participación de 95.81\% de los 2651435 electores registrados en un Estado donde votar es obligatorio (Departamento de Elecciones 2020). Además de que el PAP perdió escaños y una proporción importante del voto popular, hubo otros tres aspectos de los resultados de la elección que fueron significativos. Primero, el PAP perdió otra CRG, además de que no logró recuperar una que había perdido en las elecciones generales de 2015 ante el PT, a pesar de que muchos veían al sistema de CRG como un baluarte electoral contra una mayor presencia de la oposición en el Parlamento. ${ }^{3}$ En segundo lugar, la siguiente generación de líderes del PAP, los llamados líderes $4 \mathrm{G},{ }^{4}$ tuvieron resultados decepcionantes, pues la proporción de votos cayó varios puntos en las circunscripciones del PAP que encabezaron (Han, F. K. 2020). El fracaso en la obtención de apoyo de una base amplia de votantes perjudicó a quienes se seleccionó para ser futuros ministros del gabinete, pues muchos vieron en esta elección un intento para asegurar un mandato que ellos pudieran liderar en el futuro (Meah 2020; Thet 2020). En tercer lugar, tras la elección, el primer ministro Lee Hsien Loong

\footnotetext{
${ }^{3}$ Las CRG se introdujeron al proceso electoral en 1988. Son circunscripciones de varios miembros por las que compiten equipos de candidatos. En cada CRG al menos un candidato debe pertenecer a una raza minoritaria - malaya, india u otra. De acuerdo con el artículo 8A de la Ley de Elecciones Parlamentarias (c. 218), el objetivo de la CRG es "asegurar que en el Parlamento estén representadas la comunidad malaya, la india y otras minorías". La lógica de su implementación, según explicó un Comité Parlamentario Selecto, fue que el sistema conservaría "nuestro frágil tejido multirracial” y "consolidaría la naturaleza multirracial de nuestro Parlamento" (Information Division 1988). En este sistema se calibra que el número de escaños del Parlamento que no están ocupados por chinos sea alrededor de $25 \%$, lo que implica una representación proporcional de la población china, que asciende a aproximadamente $25 \%$ del total. Se ha criticado el sistema CRG por presentar al PAP con una ventaja competitiva sustancial, pues impone límites de facto al número de circunscripciones por el que los partidos de oposición pueden competir en una elección debido a su grupo de candidatos sustancialmente menor. Además, también se ha dicho que el sistema de CRG es una herramienta del partido gobernante para salvaguardar su dominio en el Parlamento, más que una vía para tener representación multirracial (Mutalib 2002, 659-672).

${ }^{4}$ En una adopción poco imaginativa de la nomenclatura de las normas de comunicación inalámbrica mundial —es decir, las redes $1 \mathrm{G}, 2 \mathrm{G}, 3 \mathrm{G}$ y $4 \mathrm{G}$ - a la siguiente generación de ministros que encabezará el gobierno del PAP después de que Lee Hsien Loong deje el cargo se le llama "líderes 4G".
} 
anuncio que el líder del PT Pritam Singh recibiría oficialmente el título de Líder de la Oposición -lo que establece al PT como gobierno alternativo. ${ }^{5}$

Es probable que el PAP se haya presentado a la elección con confianza. Anteriormente el partido había logrado grandes éxitos electorales durante épocas de crisis, pues el electorado singapurense parece preferir al malo por conocido en esos momentos (Yen 2020a). Por ejemplo, en las elecciones que se realizaron poco después de los ataques del 11 de septiembre de 2001, el PAP obtuvo 75.3\% de los votos. Dado el contexto de esta elección, el PAP afirmó que las EG2020 eran “elecciones de crisis” y se describió a sí mismo como la mejor opción política, entre una amplia gama de partidos alternativos, para liderar a la ciudad-Estado mientras se atraviesa la pandemia y la caída de la economía que la acompañó (Lim, Y. L. 2020b). ${ }^{6}$ Otro factor que parece favorecer una victoria considerable para el PAP fue la imposibilidad de realizar mítines políticos presenciales durante la campaña electoral. Estos mítines, que tradicionalmente eran el escenario en el que los partidos alternativos podían obtener publicidad y apoyo, no pudieron realizarse debido a las medidas de distanciamiento social que fue necesario imponer por la pandemia. Con las condiciones idóneas para una gran victoria del PAP, un analista político experimentado evitó los pronósticos moderados para declarar que las “GE2020 darán una victoria arrolladora al PAP. De hecho, la oposición podría quedar completamente aniquilada en esta elección. Los votantes singapurenses volverán corriendo con papá” (Ng 2020).

Se han citado muchas razones por las cuales el PAP perdió terreno en las EG2020. En el fondo, quizá la razón más importante es la posibilidad de que la toma de decisiones del electorado en las casillas haya pasado de los temas tangibles relacionados con el sustento, como la seguridad laboral y el costo de la vida, a cuestiones intangibles como la necesidad de tener una democracia saludable junto con los temas que conlleva. En el camino a la elección, los partidos alternativos usaron el término "no dar un cheque en blanco" para referirse a la necesidad de negar al PAP una "supermayoría" — más de dos tercios de los

\footnotetext{
${ }^{5}$ En el estilo de gobierno Westminster de Singapur, el Líder de la Oposición encabeza a la oposición en la presentación de puntos de vista alternativos en los debates parlamentarios, organiza el escrutinio de las posturas y las acciones del gobierno y se le consulta en el nombramiento de miembros de la oposición a los Comités Selectos. Se puede convocar al Líder de la Oposición para que asuma otros deberes, como asistir a los eventos oficiales de Estado y participar en visitas y reuniones junto a miembros del gobierno y el servicio público (Parliament of Singapore 2020).

${ }^{6}$ Para darse una idea de cómo el PAP confiaba en su manejo de la covid-19 y la desaceleración económica, véase su manifiesto para las EG2020, por ejemplo (PAP 2020).
} 
escaños del Parlamento, y con ello, la capacidad de aprobar modificaciones a la Constitución. En una carta dirigida al público, el doctor Tan Cheng Bock, secretario general del opositor Partido Progreso Singapur (PPS), llamó a los singapurenses a "aprovechar esta oportunidad para decirle al PAP 'se acabaron los cheques en blanco'... Voten por la transparencia y la rendición de cuentas, voten por la independencia" (Tan, C. B. 2020). Además se resaltó la necesidad de que haya más voces alternativas en el Parlamento y el argumento de que el PAP no tenía el monopolio de las mejores ideas para la sociedad (Rei 2020). Asimismo, podría decirse que el énfasis sostenido del PT durante la campaña en la necesidad de una mayor rendición de cuentas puso en aprietos al gobierno, lo cual es comprensible pues no hay una respuesta satisfactoria al llamamiento a una mayor rendición de cuentas. La mejor respuesta que el PAP pudo dar fue que el esquema de Miembros del Parlamento no Circunscripcionales (NCMP, por sus siglas en inglés) aseguraba a los singapurenses que hubiera puntos de vista diferentes al del PAP en el Parlamento. En el esquema NCMP se permite que un máximo de doce de los perdedores con mejor desempeño en unas EG sean Miembros del Parlamento (MP) sin representación circunscripcional. Si bien los NCMP gozan de los mismos derechos de voto que los MP, se ha criticado este esquema por considerársele una treta para disuadir a los votantes de votar por los MP que no pertenecen al PAP, pues se les asegura cierta forma de oposición en el Parlamento, así como un medio por el cual el sistema neutraliza a la oposición, pues no se considera que esos MP representen a las bases (Teo, X. 2011).

Otro factor que pudo haber favorecido a los partidos alternativos fue, irónicamente, la imposibilidad de realizar mítines políticos presenciales. Debido a que el internet tiene un índice de penetración de $98 \%$ en los hogares, llevar a cabo su campaña electoral en línea permitió a los partidos alternativos eludir a los medios convencionales, de inclinación oficialista, y llegar directamente a los votantes (Keiren 2020). Esta adopción del internet como herramienta de alcance durante una elección marcó un cambio de las elecciones pasadas, en las que el uso de la red fue más cauteloso y conservador (Gomez 2008). Durante las EG2020, los partidos alternativos pudieron llevar a cabo discursos y mítines en vivo y transmitirlos en línea, usar infografías para explicar sus políticas y escudriñar las posturas del PAP. Videos muy bien realizados de partidos alternativos recibieron elogios en las redes sociales y, quizá mostrando que la atención que generó esta estrategia lo tomó desprevenido, o bien en un intento de emprender acción defensiva, el PAP criticó la campaña en línea 
tildándola de "una hábil maniobra de relaciones públicas" pero incapaz de resolver los problemas del mundo real (Sholihyn 2020b). Resulta interesante que, como las EG2020 se compitieron en la red, la ventaja de la que solía gozar el PAP durante las elecciones gracias a los medios tradicionales pasivos se eliminó en cierta forma. Además de que pudieron hablarle a los votantes directamente, los partidos alternativos se beneficiaron cuando se percibía que los medios no habían sido justos en sus reportajes por dos motivos. En primer lugar, los reportes "injustos" alimentaban la percepción de que los candidatos de los partidos alternativos eran débiles pero valerosos, y en segundo, las conversaciones sobre ejemplos de reportes "injustos" dieron más publicidad a los partidos alternativos. Por ejemplo, después del encomiado desempeño de Jamus Lim, candidato del PT, en un debate televisado, se acusó a un medio tradicional de torcer la narrativa por alterar un encabezado que hablaba positivamente de Lim para hacerlo ver más halagador para el ministro de Relaciones Exteriores, su contrincante en el debate (Daud 2020). Además, la discusión de esta alteración de la narrativa generó una conversación aún mayor sobre el desempeño de Lim en las redes sociales.

Más allá de la justicia en cuanto a la forma en que los medios reportaron las elecciones, un posible motivo de la caída en la proporción de los votos para el PAP se debe a lo que alguien nombró el "Efecto Clinton” (Guimaraes 2020). Éste se refiere al paradójico aumento de popularidad del presidente estadunidense Bill Clinton a pesar del proceso de destitución que se promovió en su contra en 1998 - la popularidad de las personas puede crecer cuando el público percibe que se les trató injustamente. Aplicado en el contexto de las EG2020, el efecto explica el aumento de popularidad de los partidos alternativos, aunque el PAP haya planteado lo que puede verse como un entorno político injusto y desfavorable para el éxito de los otros partidos. Por ejemplo, algunos consideran que la Ley de elección presidencial reservada y la Ley de protección contra las falsedades y la manipulación en línea (LPFML) están diseñadas para obstaculizar los esfuerzos de quienes desafían el dominio del PAP sobre el ámbito político (Chew 2020; Wong 2020; Han, K. 2020). La creación de este ambiente pudo haber producido el resultado contrario al que deseaba el PAP, pues los votantes pudieron haber considerado que tales medidas eran injustas y causado que algunos apoyaran a los candidatos desfavorecidos. 


\section{RELACIONES EXTERIORES}

A diferencia de los problemas comunales y sanitarios que se presentaron este año en Singapur, sus relaciones exteriores pueden describirse como normales, pues se mantuvo la estabilidad entre este país y los cuatro Estados que podrían considerarse los más importantes en su constelación: Malasia, Indonesia, Estados Unidos y China.

E1 9 de agosto de 2020 fue el 55 aniversario de la separación de Singapur y Malasia. Desde entonces, el trato entre ambos países ha sido mayormente cordial, pues están íntimamente entrelazados en temas de trabajo, bienes y servicios, capital y lazos familiares. Quizá el factor más significativo para la solidez de los vínculos bilaterales en 2020 fue la renuncia en marzo de Mahathir Mohamad, primer ministro (PM) malayo, conocido por su línea dura en relación con Singapur y quien, durante su segundo reinado como PM, suspendió las obras del Sistema de Tránsito Rápido (STR) entre Johor, el estado malayo más cercano a Singapur, y un enlace ferroviario de alta velocidad entre Singapur y Kuala Lumpur. Cuando el PM Muhyiddin Yassin sustituyó a Mahathir se resucitó el proyecto del STR, y el gobierno malayo tiene hasta diciembre de 2020 para tomar una decisión sobre el proyecto del tren de alta velocidad. Ambos proyectos son sumamente importantes para ambos Estados, que comparten una de las fronteras más transitadas del mundo. Antes de la pandemia, alrededor de 300000 personas usaban los dos puentes que unen a los países, la mayoría de las cuales eran malayos que trabajaban en Singapur. Además, el vuelo de una hora entre Singapur y Kuala Lumpur, la capital de Malasia, es una de las rutas internacionales más concurridas del mundo. Se prevé que el proyecto del STR reduzca la congestión de los puentes y que el proyecto del tren de alta velocidad aumente aún más la conectividad entre Kuala Lumpur y Singapur. Si Muhyiddin permanece en el poder, se espera que su presencia fomente vínculos más fuertes, pues se dice que el PM entiende los beneficios de una relación cálida con Singapur, ya que fue ministro principal de Johor durante nueve años y su escaño parlamentario pertenecía a esa jurisdicción (Sim y Jaipragas 2020).

Las relaciones de Singapur con su otro vecino cercano, Indonesia, siguen siendo buenas durante el año. Dado que Singapur mantuvo su puesto número uno como la principal fuente de inversión extranjera directa en Indonesia, incluso durante la pandemia, no sorprende que la profundización de la relación económica sea de lo más notable de 2020. 
Tampoco sorprende que la economía domine los titulares, sobre todo porque en esta ocasión no llegó la neblina que se genera casi todos los años debido a los incendios agrícolas de escala industrial que se llevan a cabo para desmontar la tierra, y que ha tensado las relaciones en años pasados (Desker 2015). La visita de la presidente de Singapur, Halimah Yacob, a Indonesia en febrero de 2020 — su primera visita al país y también la primera visita formal de un jefe de estado singapurense al archipiélago en ocho años — brindó cierto impulso a las discusiones sobre temas económicos, por ejemplo el potencial de colaboración en los sectores emergentes, como la economía digital y la Industria 4.0. En esta visita se prepararon varios acuerdos oficiales, como el acuerdo para la eliminación de la doble imposición respecto al impuesto sobre la renta y el de Prevención de la Evasión y la Elusión Fiscales (DTA), así como un memorando de entendimiento entre la Guardia Costera Policiaca de Singapur y la Dirección General de Aduanas e Impuestos Especiales de Indonesia, que contemplaría intercambios de información y la realización de patrullajes y operativos conjuntos de manera regular, así como iniciativas de capacitación bilateral (Gorbiano 2020).

Para los tratos de Singapur con los dos gigantes de las relaciones internacionales en la región del Indo-Pacífico, 2020 siguió representando un cuidadoso acto de equilibrio para obtener el mayor espacio político posible para la toma de decisiones independiente, manteniendo una postura neutral en temas en los que Estados Unidos y China pueden estar en desacuerdo. Al igual que en otros Estados del Indo-Pacífico, se considera que esta estrategia es la óptima para obtener la presencia de seguridad estabilizadora de Estados Unidos en la región y al mismo tiempo beneficiarse del crecimiento económico de China. Muchos creen que la victoria electoral del ex vicepresidente Biden traería pocos cambios a una relación que es multifacética, pues toca diversos ámbitos como la economía, la seguridad y la educación, si no hay una "crisis bilateral urgente" (Phua 2020). Si bien tampoco existe una crisis bilateral urgente con China, la relación entre ambos países es estable pero compleja. En años anteriores hubo problemas que tensaron las relaciones. En primer lugar, la insistencia de Singapur en respetar la Convención de las Naciones Unidas sobre el Derecho del Mar (CDM) en lo relativo a las reivindicaciones de China sobre el Mar de la China Meridional es una postura que irrita a esta última, pues la ve como una internacionalización innecesaria del asunto. En segundo, el uso de Taiwán como base de adiestramiento para el ejército de Singapur también es motivo de molestia para China. Viendo hacia el futuro, la 
cuidadosa caminata de Singapur sobre la cuerda floja podría implicar algunos desafíos: principalmente la relación entre los funcionarios chinos y la siguiente generación de líderes 4G de Singapur. Lee Kwan Yew, quien fuera el primero en ocupar el puesto de PM en Singapur, y sus sucesores han sostenido muy buenas relaciones con los líderes chinos, y aún está por verse qué forma de relación pueden cultivar aquellos que están prestos a tomar el timón de Singapur (Sim 2020). Además, como ha señalado un analista, se tiene la necesidad de llegar a una relación "estable y más institucionalizada [...] basada en el derecho internacional y en el autodominio, no en los vínculos que tienen los líderes en particular" (Sim 2020). Por otro lado, aún está por verse de qué manera equilibrará Singapur a las dos potencias ahora que las compañías de tecnología chinas parecen interesadas en establecerse en Singapur. Tencent Holdings tiene planes confirmados de abrir una nueva oficina en Singapur como parte de su expansión en el Sureste Asiático, y se reporta que el gigante del comercio electrónico Alibaba Group está en proceso de realizar una inversión de 3000 millones de dólares en Grab, la empresa de transporte de pasajeros a través de aplicación, que está basada en Singapur. ByteDance, el desarrollador de la popular aplicación TikTok, también pretende invertir "varios miles de millones de dólares" en un centro de datos en Singapur, según algunos reportes. Estas maniobras podrían poner a prueba la destreza de la diplomacia singapurense si el nuevo gobierno de Estados Unidos las mira con malos ojos. Si 2020 fue un año como tantos otros en cuanto a la estrategia de Singapur para con las dos potencias, el futuro podría ser más turbulento.

\section{CONCLUSIÓN}

Si se reflexiona en torno al año en conjunto, y para resumirlo en una sola oración, 2020 fue un año en el que las relaciones exteriores de Singapur permanecieron estables, mientras que los problemas internos requirieron bastante energía. En el ámbito nacional, será interesante ver si Singapur cambia su estrategia de entrelazar el desarrollo económico con la inmigración. Además será fascinante ver cómo se adaptará el PAP a la presencia de más miembros de partidos alternativos en el Parlamento y a que su ciudadanía, normalmente dócil, se empodere con las redes sociales (si es que se adapta). Hay claroscuros en el ámbito de las relaciones exteriores. Si bien las relaciones con sus vecinos más cercanos parecen estar 
bien, aún está por verse cómo pueden equilibrarse de manera óptima las expectativas de China y las de Estados Unidos. Es interesante notar que las palabras de Run DMC, fundadores del hip hop moderno, pueden aplicarse hoy a Singapur: "hard times [are] spreading just like the flu... All day I have to work at my peak... So keep your balance, and don't you slip" [Las dificultades se contagian como la gripa... Todo el día tengo que trabajar al máximo... Así que mantén el equilibrio y no te resbales] (McDaniels et al. 1984).

Traducción: María Capetillo Lozano

Norman Vasu es profesor emérito en la Facultad de Estudios Internacionales S. Rajaratnam de la Universidad Tecnológica Nanyang en Singapur. Su investigación se centra en temas relativos al tejido social, como el nacionalismo, la inmigración y el multiculturalismo.

isnvasu@ntu.edu.sg

\section{REFERENCIAS}

Abu Baker, Jalelah y Lianne Chia. 2020. “GE2020: PAP, PSP, WP and SDP candidates take part in 'live' General Election debate." Channel News Asia, julio 2, 2020. https:// www.channelnewsasia.com/news/singapore/ge2020-live-broadcast-political-debatepap-wp-sdp-psp-12891964

Barron, Laignee. 2020. "What We Can Learn from Singapore, Taiwan and Hong Kong About Handling Coronavirus." Time, marzo 13, 2020. https://time.com/5802293/ coronavirus-covid19-singapore-hong-kong-taiwan/

Bellows, Thomas J. 1990. “Singapore in 1989: Progress in a Search for Roots.” Asian Survey 30 (2): 203. https://online.ucpress.edu/as/article-abstract/30/2/201/22657/Singaporein-1989-Progress-in-a-Search-for-Roots

Cher, Andrew. 2020. "Countries in lockdown should do what Singapore has done, says coronavirus expert." CNBC, marzo 31, 2020. https://www.cnbc.com/2020/03/31/ countries-in-lockdown-should-try-what-singapore-is-doing-coronavirus-expert.html 
Chew Hui Min. 2020. "In Focus: A General Election with a 'Covid twist' - how a pandemic may shape a pivotal contest." Channel New Asia, junio 24, 2020. https:// www.channelnewsasia.com/news/singapore/in-focus-ge-general-election-covid19$\underline{\text { issues-economy-jobs-12857392 }}$

Daud, Sulaiman. 2020. "AsiaOne clarifies headline change on political debate, independent decision made with no external communication." Mothership, julio 3, 2020. https://mothership.sg/2020/07/asiaone-clarifies-headline-change-political-debate/

Desker, Barry. 2015. "Hazy days strain Singapore-Indonesia relations." East Asia Forum, octubre 22, 2015. https://www.eastasiaforum.org/2015/10/22/hazy-days-strainsingapore-indonesia-relations/

Elections Department. 2020. "Press Release. Total Votes Cast at Singapore General election 2020.” Elections Department Prime Minister's Office, julio 15, 2020. https:// www.eld.gov.sg/press/2020/Press_Release_on_Total_Votes_Cast_at_Singapore_Ge neral_Election_2020.pdf

“Entry of Hongkongers Won’t Upset Racial Mix.” 1989. The Straits Times, agosto 21, 1989.

Fordyce, Deborah D. 2020. “Employers' practices leave foreign workers vulnerable to infection." The Straits Times, marzo 23, 2020. https://twc2.org.sg/2020/03/23/straits$\underline{\text { times-forum-employers-practices-leave-foreign-workers-vulnerable-to-infection/ }}$

Gomez, James. 2008. “Online Opposition in Singapore: Communications Outreach Without Electoral Gain.” Journal of Contemporary Asia 38 (4): 591-612.

Gorbiano, Marchio Irfan. 2020. “Indonesia, Singapore reaffirm economic, people-to-people relations." Jakarta Post, febrero 5, 2020. https://www.thejakartapost.com/news/ $\underline{\text { 2020/02/05/indonesia-singapore-reaffirm-economic-people-people-relations.html }}$

Griffiths, James. 2020. "Singapore had a model coronavirus response, then cases spiked. What happened?' $C N N$, abril 19, 2020. https://edition.cnn.com/2020/04/18/asia/ $\underline{\text { singapore-coronavirus-response-intl-hnk/index.html }}$ 
Guimaraes, Conrad. 2020. "Singapore's 2020 Election: Explaining the PAP's Stagnation." The Diplomat, agosto 5, 2020. https://thediplomat.com/2020/08/singapores-2020election-explaining-the-paps-stagnation/

Han Fook Kwang. 2020. "Singapore GE2020: Vote signals a desire for change, but not in a hurry.” The Straits Times, julio 12, 2020. https://www.straitstimes.com/opinion/votesignals-a-desire-for-change-but-not-in-a-hurry

Han, Kirsten. 2020. "Want to Criticize Singapore? Expect a 'Correction Notice'." The New York Times, enero 21, 2020. https:/www.nytimes.com/2020/01/21/opinion/fakenews-law-singapore.html

Heijmans, Philip y Jason Gale. 2020. “As Asia Panics, One Country Wins Praise for Approach to Virus.” Bloomberg, febrero 10, 2020. https://www.bloomberg.com/ news/articles/2020-02-10/as-asia-panics-one-country-wins-praise-for-approach-to$\underline{\text { virus }}$

Hodal, Kate. 2013. "Singaporean Protest: 'Unfamiliar faces are crowding our land." The Guardian, febrero 15, 2020. http://www.theguardian.com/world/2013/feb/15/ $\underline{\text { singapore-crisis-immigration-financial-crisis }}$

Hong, Lynda. 2017. “Aligning to work as one.” Challenge, octubre 7, 2017. https://www.psd. gov.sg/challenge/ideas/deep-dive/aligning-to-work-as-one

Information Division. 1988. Group Representation Constituencies: A summary of the report of the Select Committee. Singapur: Ministry of Communications and Information.

Jones, Joseph. 2010. “The Property Blame Game.” iProperty.com, noviembre 4, 2010.

Keiren Goh 2020. "Singapore General Elections: New Dawn for the Opposition?" The Diplomat, julio 9, 2020. https://thediplomat.com/2020/07/singapore-generalelections-new-dawn-for-the-opposition/

Khan, Asif Ullah. 2020. "Why Have Singaporeans Turned Against Indian Professionals?" The Diplomat, octubre 8, 2020. https://thediplomat.com/2020/10/why-havesingaporeans-turned-against-indian-professionals/ 
Koay, Andrew y Belmont Lay. 2020. “American science journalist praises S'pore's Covid19 fight: If S'pore can't do it, we're all screwed." Mothership, febrero 18, 2020. https:/mothership.sg/2020/02/laurie-garrett-singapore-covid-19/

Kok Xinghui. 2020. "Singapore unveils fourth stimulus budget of US $\$ 23.2$ billion to save jobs." South China Morning Post, mayo 26, 2020. https://www.scmp.com/weekasia/politics/article/3086106/singapore-unveils-fourth-stimulus-budget-us232billion-save-jobs

Lee Hsien Loong. 2010. “National Day Rally Speech.” Prime Minister's Office Singapore, agosto 29, 2010. https://www.pmo.gov.sg/Newsroom/prime-minister-lee-hsienloongs-national-day-rally-2010-speech-english

Lee, Joshua. 2020. "Covid-19 outbreak in dorms due to migrant workers' poor hygiene \& bad habits: Zaobao forum letter." Mothership, abril 15, 2020. https:// mothership.sg/2020/04/migrant-workers-zaobao-letter/

Leonhardt, David. 2020. "The Singapore Warning Reopening the economy will be hard." The New York Times, abril 16, 2020. https://www.nytimes.com/2020/04/16/opinion/ coronavirus-reopen-economy-singapore.html

Lim Min Zhang. 2020. "Coronavirus: Migrant workers important to S'pore economy, say business and trade groups in response to calls to limit numbers." The Straits Times, mayo 27, 2020. https://www.straitstimes.com/singapore/business-and-trade-groupsunderline-importance-of-migrant-workers-to-singapore-economy

Lim Yan Liang. 2020a. "Coronavirus: Letter on dorm cases xenophobic, says Shanmugam." The Straits Times, abril 18, 2020. https://www.straitstimes.com/singapore/letter-ondorm-cases-xenophobic-shanmugam

Lim Yan Liang. 2020b. "Singapore GE2020: This is a crisis election that will shape Singapore's future, says PM Lee.” The Straits Times, junio 30, 2020. https://www. straitstimes.com/politics/singapore-ge2020-this-is-a-crisis-election-that-will-shapesingapores-future-says-pm-lee 
Low, Donald. 2020. "How Singapore can draw the right lessons from the coronavirus crisis." South China Morning Post, abril 16, 2020. https://www.scmp.com/week-asia/ opinion/article/3080095/how-singapore-can-draw-right-lessons-coronavirus-crisis

Low, James. 2020. “Covid-19 Crisis Management: An Early Look.” Ethos, junio 3, 2020. https://www.csc.gov.sg/articles/covid-19-crisis-management-an-early-look

Lur, Zavier. 2011. "Singaporean students fell the heat from foreign counterparts." Yahoo.com, octubre 24, 2020. http://sg.news.yahoo.com/blogs/what-is-buzzing/ porean-students-feel-heat-foreign-counterparts-114119914.html

Mathews, Mathew y Shamil Zainuddin. 2020. "The pandemic, moral panic and 'folk devils'." The Straits Times, mayo 8, 2020. https://www.straitstimes.com/opinion/thepandemic-moral-panic-and-folk-devils

McDaniels, D., J. Simmons, L. Smith y W. Warring. 1984. "Hard Times." Run-DMC. Arista Records LLC.

Meah, Natasha. 2020. "GE2020: Sengkang GRC a 'major loss' to 4G team, says PM Lee." Today, julio 11, 2020. https://www.todayonline.com/singapore/sengkang-grc-majorloss-4g-team-says-pm-lee

Moore, Malcolm. 2011. “Singapore's 'anti-Chinese curry war.” Telegraph, agosto 16, 2020. http://www.telegraph.co.uk/news/worldnews/asia/singapore/8704107/Singaporesanti-Chinese-curry-war.html

Mutalib, Hussin. 2002. "Constitutional-electoral reforms and politics in Singapore." Legislative Studies Quarterly 27 (4): 659-672.

Ng, Nelly. 2020. "This NUS Professor Predicts That GE2020 Will Be a Landslide Victory for the PAP." The Kopi, junio 26, 2020. https://thekopi.co/2020/06/29/bilveer-singhpredicts-will-be-a-landslide-victory-for-the-pap/

PAP (People's Action Party). 2020. “Manifesto.” https://www.pap.org.sg/manifesto/\#

Parliament of Singapure. 2020. "Duties and Parlamentary Privileges of Leader of the opposition." Office of the Speaker of Parliament and Office of the Leader of the 
House, julio, 28, 2020. https://www.parliament.gov.sg/docs/default-source/defaultdocument-library/press-release-on-leader-of-opposition.pdf

Persek, William. 2013. “'Ponzi demography' as Singaporeans fear overpopulation bubble, burst.” The Japan Times, febrero 25, 2020. https://www.japantimes.co.jp/opinion/ 2013/02/25/commentary/world-commentary/ponzi-demography-as-singaporeansfear-overpopulation-bubble-burst/

Phua, Rachel. 2020. "Little change to US-Singapore relations under either Trump or Biden: Experts." Channel News Asia, noviembre 4, 2020. https://www.channelnewsasia. com/news/singapore/singapore-us-relations-trump-biden-us-elections-2020-vote13461760

Ratcliffe, Rebecca. 2020. “We're in a prison': Singapore's migrant workers suffer as Covid19 surges back." The Guardian, abril 23, 2020. https://www.theguardian.com/ world/2020/apr/23/singapore-million-migrant-workers-suffer-as-covid-19-surgesback

Rei Kurohi. 2020. "Singapore GE2020: WP wants to deny PAP a blank cheque, says Jamus Lim.” The Straits Times, septiembre 2, 2020. https://www.straitstimes.com/politics/ voters-being-asked-for-blank-cheque-says-wp

Seah Chiang Nee. 2009. "Sports Highlight the Growing Ire.” The Star Online, junio 13, 2009. http://www.thestar.com.my/story.aspx/?file=\%2f2009\%2f6\%2f13\%2ffocus $\% 2 \mathrm{f} 409$ 9934\&sec $=$ focus

Sholihyn, Ilyas. 2020a. "Amid global backlash against colonialists, netizens ask what about Raffles?" AsiaOne, junio 11, 2020. https://www.asiaone.com/digital/amid-globalbacklash-against-colonialists-netizens-ask-what-about-raffles

Sholihyn, Ilyas. 2020b. "PAP's Shanmugam throws shade at 'slick PR videos' put out by other parties in GE2020.” AsiaOne, julio 1, 2020. https://www.asiaone.com/singapore/ paps-shanmugam-throws-shade-slick-pr-videos-put-out-other-parties-ge2020

Singapore Department of Statistics. s. f. "Births and Fertility." https://www.singstat. gov.sg/find-data/search-by-theme/population/births-and-fertility/latest-data 
Sim, Dewey. 2020. "Singapore-China relations, 30 years on: can the 4G leaders hold their own, and will the US rock the boat?" South China Morning Post, octubre 3, 2020. https://www.scmp.com/week-asia/politics/article/3103994/singapore-chinarelations-30-years-can-4g-leaders-hold-their-own

Sim, Dewey y Bhavan Jaipragas. 2020. "Stalled Malaysia-Singapore metro link gets fresh push as ties thaw post-Mahathir." South China Morning Post, julio 30, 2020. https:/www.scmp.com/week-asia/politics/article/3095299/stalled-malaysia-singaporemetro-link-gets-fresh-push-ties-thaw

Surowiecki, J. 2004. The wisdom of crowds: Why the many are smarter than the few and how collective wisdom shapes business, economies, societies, and nations. Nueva York: Doubleday \& Co.

Tai, Janice. 2020. "Racism and xenophobia resurfacing during Covid-19: MCCY minister Grace Fu." The Straits Times, mayo 30, 2020. https://www.straitstimes.com/ singapore/racism-and-xenophobia-resurfacing-during-covid-19-mccy-ministergrace-fu

Tan Cheng Bock. 2020. 'Singapore GE2020: Say 'no More Blank Cheques' to the Ruling Party, Says Dr Tan Cheng Bock.” The Straits Times, julio 3, 2020. https://www. straitstimes.com/singapore/say-no-more-blank-cheques-to-the-ruling-party-dr-tan

Tan, Eugene K. B. 2020. "Time for Singapore to address some uncomfortable questions on its migrant workers." Today, abril 29, 2020. https://www.todayonline.com/ commentary/time-singapore-address-uncomfortable-questions-migrant-workerscovid-19-dormitories

Teh Joo Lin y Cheryl Lim. 2011. "Stand for Election? ‘Ensure Male Candidates do NS First'.” The Straits Times, mayo 3, 2011.

Teo Cheng Wee y Robin Chan. 2011. "PAP Salvo Targets Workers' Party 'Star' Chen.” The Straits Times, abril 19, 2020.

Teo Xuanwei. 2011. "Low Thia Kiang: No NCMP seat for me.” Today, marzo 24, 2020. 
Thet, Nyi Nyi. 2020. “ST’s editor-at-large: PAP’s leadership succession, who will be next PM, should be reviewed.” Mothership, julio 12, 2020. https://mothership.sg/2020/07/4gpost-election-heng-swee-keat/

Today, 2020a. "Facing job uncertainty and online vitriol, expats in S'pore share their worries and anxieties." Today, septiembre 6, 2020. https://www.todayonline.com/big-

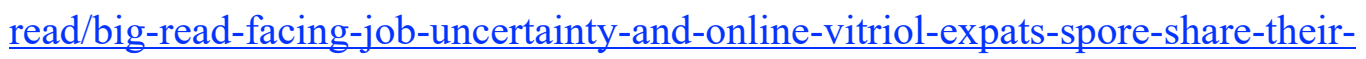
worries-and

Today, 2020b. “The Big Read: From 'gold standard' to 'cautionary tale' - dissecting first 3 months of S'pore's Covid-19 response." Today, abril 25, 2020. https://www. todayonline.com/big-read/big-read-gold-standard-cautionary-tale-dissecting-first-3months-spores-covid-19-response

Vasu, Norman y Yasmine Wong, 2020. “BLM Movement: Singapore and Glocalisation.” RSIS Commentaries, julio 13, 2020. https://www.rsis.edu.sg/rsis-publication/cens/blmmovement-singapore-and-glocalisation/

Wong, Tessa. 2020. "Why Singaporeans aren't all glad to get the president they wanted." $B B C$ News, septiembre 13, 2020. https://www.bbc.com/news/world-asia-41237318

Yen Nee Lee. 2020a. "5 reasons why Singapore's upcoming general election is worth watching." $C N B C$, julio 1, 2020. https://www.cnbc.com/2020/07/01/5-reasons-whysingapores-upcoming-general-election-is-worth-watching.html

Yen Nee Lee. 2020b. "Singapore announces another $\$ 5.8$ billion to boost its coronavirus-hit economy." $C N B C$, agosto 17, 2020. https:/www.cnbc.com/2020/08/17/singaporeannounces-another-5 point8-billion-to-boost-its-coronavirus-hit-economy.html

Zhang, Jane. 2020. “Ong Ye Kung: Racial insensitivities exist in S'pore, but our situation 'entirely different' from US.” Mothership, junio 6, 2020. https://mothership.sg/2020/ $\underline{06 / \text { racial-microaggressions-ong-ye-kung/ }}$ 